Seale C. (2009) Hastening death in end-of-life care: a survey of doctors. Social Science and Medicine, 69(11):1659-1666

\title{
Hastening death in end-of-life care: a survey of doctors
}

\section{Abstract}

In end-of-life care the application of medical technology to prolong life at the expense of quality of life is widely debated. A national survey of 3,733 UK doctors reporting on the care of 2,923 people who had died under their care is reported. There was no time to make an 'end-of-life decision' (deciding to provide, withdraw or withhold treatment) for $8.5 \%$. A further $55.2 \%$ reported decisions which they estimated would not hasten death and $28.9 \%$ reported decisions they had expected to hasten death. A further $7.4 \%$ reported deaths where they had to some degree intended to hasten death $(=100 \%)$. Where patients or someone else had made a request for a hastened death, doctors were more likely to report expecting or at least partly intending to hasten death. Doctors usually made these decisions in consultation with colleagues, relatives and, where feasible, with patients. Intensive care specialists were particularly likely to report a degree of intention to hasten the end of life and to have treated patients lacking the capacity to discuss these decisions. Palliative medicine specialists were the least likely to report decisions they expected or at least partly intended to end life, in spite of reporting a high incidence of requests from their patients for a hastened death. Doctors with strong religious beliefs or who opposed the legalisation of assisted dying were unlikely to report such decisions. Elderly women and those with dementia are groups considered vulnerable in societies where a permissive approach is taken to hastening death in end-of-life care, but doctors describing these deaths were no more likely to report decisions which they expected or at least partly intended to end life. The survey suggests that concerns about the sanctity of life, as well as estimates of the quality of life, enter clinical decision-making. 
The medical care of people nearing the end of life often involves doctors in making decisions about whether to provide, withhold or withdraw treatments, in the knowledge that these actions may have an impact on length of life. Additionally, in some jurisdictions there is the option of intervening with the sole purpose of ending life (assisted dying, which includes physician-assisted suicide, euthanasia and lifeending without the patient's request). Prospects for recovery with an acceptable quality of life and the extent of existing suffering that further treatment may prolong, are central considerations for many doctors, although concern about the sanctity of life drives ethical objections to assisted dying. In addition, decisions can be influenced by the wishes of patients, where these can be ascertained, and of their families perhaps particularly when patients are unable to communicate.

This paper reports a survey of doctors to estimate the prevalence of decisions involving the expectation or intention that these will hasten death, to establish how this varies across different medical specialties and care settings, and to establish the degree to which patients and families are involved in, or indeed make requests for these decisions. The survey produces results pertinent to the 'slippery slope' argument against permitting assisted dying, and demonstrates associations between doctors' religious beliefs and their clinical decisions. The study is therefore an empirical contribution to debates in bioethics. 


\section{Background}

Historical evidence (Kemp, 2000) suggests that doctors in the latter half of the twentieth century have become increasingly reluctant to apply medical technology to prolong life at all costs. The further step, in which intention to end life becomes the predominant motive, as in euthanasia or physician-assisted dying, is much more contentious and is not legal in the UK. Yet it is clear that even in a jurisdiction where assisted dying is not permitted, doctors may take decisions which they expect to contribute to the ending of life since, they may take the view that an action is acceptable where the primary intention is to relieve the suffering of a person close to death. Establishing the prevalence of what are sometimes called 'double effect' decisions is therefore the first purpose of this study.

Caregivers across a variety of settings, including patients' own homes, care homes, palliative and other hospital care settings have reported requests from patients and families for assistance in dying (see, for example, studies in the USA by Carlson, Simopoulos, Goy, Jackson, \& Ganzini, (2005), Ganzini, Fenn, Lee, Heintz \& Bloom, (1996), Ganzini, Harvath, Jackson, Goy, Miller, \& Delorit (2002), Miller, Harvath, Ganzini, Goy, Delorit, \& Jackson (2004), Schmidt, Zechnich, Tilden, Lee, Ganzini, Nelson \& Tolle (1996)). They are particularly common in hospice and palliative care settings (Seale \& Addington-Hall, 1995b) and in patients with cancer (Emanuel 2002; Marquet, Bartelds, Visser, Spreeuwenberg \& Peters, 2003). A further purpose of this study is to relate the incidence of such requests to the incidence of decisions where the doctor reports a decision which they expected or at least partly intended to hasten 
the end of life. In addition the extent to which doctors communicate about such decisions with patients and others is reported.

Attitudes towards these ethically contentious decisions differ between doctors and the general public and within each of these groups, reflecting the tension between quality of life and sanctity of life considerations. Studies of the general population show that the religious, the less educated, non-whites and disabled people are less likely to endorse assisted dying (Clery, McLean \& Phillips, 2007). In most countries where comparative research has been done, doctors are much less likely than the general public of those countries to endorse the legalisation of assisted dying (see, for example, Emanuel (2002)) and this has now been shown to apply also in the UK (Seale, 2009a).

Within medical opinion there are marked variations. Seale's (2009a) review of this literature cites studies showing that, as in studies of the general public, religion makes a difference (see, for example, Georges, Onwuteaka-Philipsen, van der Heide, van der Wal \& van der Maas, 2006)) as does medical specialty. Oncologists, geriatricians and palliative care doctors have been found to be particularly opposed to assisted dying (Miccinesi, Fischer, Paci, Onwuteaka-Philipsen, Cartwright, van der Heide et al, 2005; Seale, 2009a) and intensive care physicians most supportive (Dickinson, Lancaster, Clark, Ahmedzai \& Noble, 2002). Dickinson, Clark, Winslow and Marples (2005) review studies of American physicians, showing they are more willing to support physician-assisted suicide than active voluntary euthanasia. Whether attitudes influence clinical decision-making is a relatively unexplored issue, with the exception of Slome, Mitchell, Charlebois, Benevedes \& Abrams (1997) who found that doctors 
in San Francisco with high 'intention to assist' attitude scores did in fact assist more people with AIDS to die. The present study therefore investigates whether there is an association between doctors' attitudes or beliefs and their reports of decisions which they expect or at least partly intend to end life.

Concern has been expressed (Saunders, 1992; George, Finlay \& Jeffrey 2005; Finlay, 2006) that the legalisation of assisted dying could lead to a 'slippery slope' in which the lives of elderly people or those without the capacity to express themselves, become devalued. For example, there is some evidence (Seale \& Addington-Hall, 1995a) to suggest that very elderly people - particularly elderly widows - are less likely to have family members with a strong emotional investment in the prolongation of their lives. Evidence from Switzerland where there is less regulation and monitoring of assisted dying than in other countries (Bosshard, Fischer \& Bär, 2002) may support this, as this shows that the practice incorporates significant numbers of elderly women without terminal illness (Bosshard, Ulrich \& Bär, 2003; Frei, Schenker, Finzen, Kräuchi, Dittman \& Hoffman-Richter, 2001). Where permissive legislation is accompanied by regulatory requirements to prevent abuse, statistical surveys have produced no evidence to suggest a slippery slope scenario (Bilsen, van der Stichele, Broeckaert, Mortier \& Deliens, 2007; van der Heide, OnwuteakaPhilipsen, Rurup, Buiting, van Delden, Hanssen-De Wolf, et al, 2007). A final purpose of this study is therefore to establish whether groups sometimes considered vulnerable to the 'slippery slope' (elderly women, people with dementia) in fact experience a different rate of decisions where the doctor expected or at least partly intended to hasten death. 
This study therefore aims:

1. To estimate the prevalence of end-of-life care decisions which doctors expect or at least partly intend to hasten death, and to establish how this varies across different care settings, medical specialties and patient groups.

2. To examine the role which religious beliefs and attitudes towards the legalisation of assisted dying are associated with readiness to take decisions doctors expect or at least partly intend to end life.

3. To assess the degree to which requests for a hastened death from patients, relatives or others, are associated with the incidence of decisions involving an expectation or some intention to end life, and the extent to which such decisions are discussed with patients, relatives or others.

4. To assess whether such decisions occur disproportionately in groups of patients considered vulnerable. 


\section{Methods}

\section{Sample and questionnaire return}

Binley's database (www.binleys.com) of 76,459 UK medical practitioners was used to send questionnaires to 8857 working UK medical practitioners, comprising separate random samples of 2829 general practitioners (7\% of GPs listed by Binleys), 443 neurologists ( $43 \%$ of neurologists listed), 836 specialists in care of the elderly ( $21 \%$ of these doctors), 462 specialists in palliative medicine (54\% of these doctors) and 4287 in other hospital specialties (excluding specialties such as public health where doctors do not normally treat people who die, so $15 \%$ of these doctors).

Neurologists, palliative medicine and care of the elderly specialists were over sampled in relation to their proportions in the medical population to enable exploration of the circumstances of elderly people, people receiving specialist palliative care, and those with multiple sclerosis (MS) and motor neurone disease (MND). The mailing and two follow-up reminders were sent, with postage-paid reply envelopes, between November 2007 and April 2008. The sensitive nature of the subject matter was addressed by ensuring (as in earlier surveys using this method) that respondents knew their replies could not be traced back to them. No identifying marks were placed on the questionnaire, and a card was returned by respondents separately to indicate that a response had been made and no further reminders should be sent. 


\section{Questionnaire}

A structured questionnaire designed for doctors asked for respondents' age, gender, medical specialty and the number of deaths they attended on average in the normal course of their duties in either a week, a month or a year. If doctors reported having attended a patient who died in the past year they were asked a series of other questions about the age, gender, place of death and cause of death of the last deceased patient they had attended, and how long they had known the patient before death. They were then asked the questions about end-of-life decisions shown in Box 1 .

\section{Box 1: Questions about end-of-life decisions}

Respondents who answered 'yes' to any of the items in Q2, 3, 4 or 5 were asked which were the most important reasons for the last-mentioned act or omission, and were given the response options shown in Table 6 , being asked to indicate any that applied. They were asked to say by how much they thought the patient's life had been shortened by this act or omission and whether they had discussed it with the patient, either at the time of performing it or some time beforehand. They were asked whether this discussion had included the (probable or certain) hastening of the end of life by this act or omission. They were also asked whether the decision had been taken in response to an explicit request from the patient.

Whether the act or omission was discussed or not, all respondents answering 'yes' to any of the items in Q2, 3, 4 or 5 were asked whether they had thought the patient had capacity to assess his or her situation and make a decision about it. These respondents were then asked to indicate anybody else (medical colleagues, nursing staff or other caregivers, a partner or relatives of the patient or someone else) with whom they had 
discussed the possible hastening of the end of the patient's life by the last mentioned act or omission.

All respondents, regardless of their answers to the questions in Box 1, were then asked whether an explicit request to hasten the end of life was made by a partner or relatives of the patient, nursing or other care staff or someone else, whether the patient had themselves ever expressed a wish (either clearly or not very clearly) for the end of his or her life to be hastened and whether this had reduced or disappeared over time. Where it was considered to have reduced or disappeared, respondents were asked whether this had occurred in response to care provided or for some other reason. Respondents were also asked four questions about their attitudes towards the legalisation of euthanasia and physician-assisted suicide, and a question about the strength of any religious beliefs, these questions being worded as for the British Social Attitudes survey (Clery, McLean \& Phillips, 2007) (see also Seale, 2009a).

\section{Response rate and response bias}

Specialists in palliative medicine produced the highest response rate $(67.3 \%)$, then specialists in care of the elderly (48.1\%), neurologists (42.9\%), other hospital specialties $(40.1 \%)$ and general practitioners $(39.3 \%)$. The overall response rate was $42.1 \%$ (3733 doctors).

An investigation of response bias is reported more fully elsewhere (Seale, 2009a). To summarise: comparisons of responding doctors with national medical workforce statistics and a survey of non-responders were done. As in a similar investigation of non-response (Fischer, Miccinesi, Hornung, Bosshard, Deliens, van der Heide et al, 
2006) non-responders were not significantly different from responders in their degree of support for euthanasia or physician-assisted suicide. Non-responders tended to be younger, to have inadequate time to complete the questionnaire, and to believe it was only relevant to reply if they normally attended to dying patients or were involved in terminal care. The patients reported on by responders were more likely to have died from cancer and less likely to have died from cardiovascular disease, than in national mortality statistics.

\section{Analysis}

The questions in Box 1 were used to construct a variable indicating whether a death was accompanied by:

a. no end-of-life decision ('no' to all three Q1 items),

b. a decision that involved no expectation by the doctor of a life-shortening effect ('yes' to one of the items under Q1; 'no' to all other questions)

c. a decision involving an expectation by the doctor that it could hasten the end of life ('yes' to one or more of the items under Q1 and to one or more of Q2a, Q2b, Q3a but 'no' to all others)

d. a decision containing at least some intention by the doctor to hasten the end of life ('yes' to one or more of Q3b, Q4a, Q4b and Q5)

The questions about attitudes towards the legalisation of euthanasia and physicianassisted suicide were combined to produce a four-point scale ranging from 4 , meaning high support for assisted dying, to 1, meaning high opposition to assisted dying. 
In the event, low numbers of MS and MND deaths were reported, so neurologists were combined with 'other hospital specialties' for the present analysis where comparisons of specialty are made. For the analyses reported in this paper all data for results reported below this point are weighted by doctor's specialty to mirror proportions of specialities in the medical population and by the number of deaths normally attended by each doctor in one year, so that doctors attending fewer deaths are not overrepresented. The survey as reported here is, then, intended to be representative of the medical population rather than the population of deaths. The rationale for variable selection for the multivariate analysis in Table 4 involved excluding variables that showed multicollinarity with included variables, and including those with theoretical importance for the research questions (rather than solely their statistical significance in bivariate analysis). Occasional case studies of individuals are reported in the text, derived from free text written by respondents (placed in quote marks) and responses to fixed-choice questions for that case.

\section{Results}

In $2855 / 2923$ cases where a doctor reported having attended a patient who died in the last twelve months, doctors answered the questions about end-of-life decisions (68 missing cases).

(a): Deaths with no end-of-life decisions

In $8.5 \%(242 / 2855)$ of cases doctors said that no drugs were given to alleviate pain or other symptoms and no treatment was withdrawn or withheld (ie: answered 'no' to Q1a, b and c in Box 1). Such cases were somewhat more common for doctors 
reporting deaths in hospitals (10.1\% of 1892 hospital deaths) and in care homes (10.2\% of 186 deaths in care homes). They were less common for doctors reporting deaths in private homes $(5.5 \%$ of 477$)$ and hospices $(1.4 \%$ of 280$)\left(X^{2}\right.$ test; $\mathrm{p}<0.0005)$. They were more likely amongst doctors reporting on the deaths of patients aged 80 or more $(10.8 \% ; 109 / 1013$ as opposed to $7.1 \% ; 130 / 1828$ younger patients; $X^{2}$ test; $\left.\mathrm{p}<0.0005\right)$.

Two medical specialties contributed high numbers of such deaths: specialists in the care of the elderly (14.4\%; 44/306 such specialists) and doctors specialising in accident and emergency or trauma $(21.9 \% ; 35 / 160)$ (specialists in diabetes, gastroenterology, renal medicine and neurosurgery also reported high rates $(15.5 \%$; 37/238)). No palliative medicine specialists reported such deaths (0/247) and they were also rare for hospital doctors describing themselves as oncologists (1/121 oncologists) and ICU or critical care specialists (1/69 ICU specialists), in all of which settings one would expect patients to receive treatment interventions.

Consistent with this finding is the fact that doctors reporting on deaths from cancer were particularly unlikely to say that these involved no end-of-life decision (2.9\%; $36 / 1230$ compared with $13.0 \%$ of other deaths; $X^{2}$ test; $\left.p<0.0005\right)$ and that this pattern was more likely when doctors also reported having known the patient for less than 24 hours before death $\left(16.2 \% ; 61 / 376\right.$ as opposed to $7.1 \% ; 174 / 2459 ; X^{2}$ test; $\left.p<0.0005\right)$. Knowing a patient for less than 24 hours before death was more likely to occur in hospital deaths $(19 \% ; 356 / 1519)$ than in deaths elsewhere $(2.4 \% ; 23 / 953)\left(X^{2}\right.$ test; $\mathrm{p}<0.0005$ ), and particularly likely to be reported by doctors specialising in accident 
and emergency or trauma $(92.9 \% ; 143 / 154$ of these doctors compared with $8.7 \%$;

232/2673 of all other doctors; $X^{2}$ test; $\mathrm{p}<0.0005$ ).

Examples of two deaths of this sort are as follows:

A woman in her 70s who died of myocardial infarction in hospital, attended by a specialist in emergency medicine who first saw her less than 24 hours before death, writing 'Working in emergency medicine, the majority of deaths I deal with are cardiopulmonary arrests' (E1472)

A woman in her 80 s with vascular dementia who died of pneumonia in a care home, reported by a consultant specialising in old age psychiatry who had known her for more than six months. (D0172)

\section{(b): Deaths with decisions but no shortening of life anticipated}

A further 55.2\% (1577/2855) of doctors who had attended a death reported a drug having been given to alleviate pain or other symptoms, or a treatment having been withdrawn or withheld, but estimated no possibility that this would have influenced length of life. In the analysis that follows, these deaths are categorised as involving 'no expectation' of hastening the end of life. Table 1 shows that these decisions were reported most often by specialists in palliative care and least often by doctors working in 'other hospital' specialties. Table 2 shows that they were more common where patients died of cancer and for those dying in a hospice or palliative care unit. They were also reported more often by doctors who were religious and who opposed assisted dying. Examples of this kind of decision included the following: 
A man in his 50s who died of cancer in his own home, reported by a specialist in palliative medicine who had known him for more than six months. He was mildly sedated with midazolam and was also given morphine and other drugs. A decision had been made to withhold CPR and artificial nutrition, and blood transfusions and some other medications had been withdrawn. None of these decisions were felt to be linked to any potential hastening of the end of life. The doctor wrote: 'Often patients and family think that you give medication to 'let them slip away' and 'increase the morphine until they are dead'. We do try to clarify that this is neither our intention nor practice.' (A0057)

A man in his 80 s who died of cardiac failure in hospital, reported by a GP who had known him for more than six months. He had been given morphine during the last day of his life but no other drugs. 'Routine prophylactic treatments...aspirin, statins etc' had been discontinued. None of these decisions were felt to be linked to any potential hastening of the end of life. (B0125)

Deaths with decisions $(c)$ expected or $(d)$ intended by doctors to hasten the end of life In $28.9 \%(825 / 2855)$ of cases doctors took an end-of-life decision and agreed that they had considered it probable or certain that withdrawing or withholding a treatment, or giving a drug for pain or other symptoms, would hasten the end of the patient's life. These decisions are categorised for the purpose of this analysis as involving 'expectation' that this could occur (type (c) decisions). 
A further $7.4 \%(211 / 2855)$ said that in giving a drug they had partly intended to end life or had the explicit intention of doing this, or that in withholding or withdrawing treatment they had the explicit intention of hastening the end of life, categorised in the analysis that follows as involving 'intention' (type (d) decisions).

The rest of the analysis in this section compares deaths with end-of-life decisions where no shortening of life was anticipated by the doctor (type (b) decisions), with deaths with a decision where there was either (c) expectation or (d) intention to end life by the doctor. Deaths with no end-of-life decision (type (a)) are excluded.

Table 1: Expectation and intention to hasten death, by doctors' characteristics (percentages)

Table 1 shows that older doctors are more likely than younger doctors to both report an intention to hasten the end and to report an action with no expectation. Younger doctors are more likely to report an action with an expectation that it could end life. Male doctors are more likely to report an action with expectation or intention. Specialists in palliative medicine are the least likely to take actions with expectation or intention, and doctors in 'other hospital' specialties the most likely. Supporting the legalisation of assisted dying and being non-religious are both associated with greater likelihoods of reporting actions expected and intended to hasten death.

Table 2: Expectation and intention to hasten death, by patients' characteristics (percentages) 
Table 2 shows patients' age and gender are unrelated to whether actions with an estimated impact on length of life were reported. Deaths in hospital are more likely to involve actions with expectation or intention to shorten life and deaths in hospices or PCUs or from cancer less likely. Deaths in hospice or palliative care units are particularly unlikely to involve these actions. Whether a patient had dementia is not associated with expectation or intention, but a high level of intention to hasten death is associated with patients being judged to lack capacity.

Table 3: Expectation and intention to hasten death, by requests for a hastened death (percentages)

Table 3 shows that requests for a hastened death from patient and, particularly, from relatives are associated with a greater incidence of actions taken with the expectation or intention of hastening death. The same is true for the small number of requests reported from nursing and other care staff.

Table 4: Logistic regression of $(c)$ expectation or $(d)$ intention to hasten death versus decisions with (b) no expectation or intention, on specialty, cause of death, request for a hastened death, capacity and attitude to legalisation of assisted dying.

The logistic regression in Table 4 shows that being in favour of assisted dying, reporting a request for a hastened death and reporting on the care of someone judged to lack capacity independently increase the odds of reporting a decision taken with expectation or intention to hasten the end of life. Palliative care doctors are extremely 
unlikely to report this, with doctors working in hospital specialties other than care of the elderly being over eight times more likely to report this than palliative care doctors. The association with cause of death evident in bivariate analysis (see Table 2) is no longer significant in this multivariate analysis

An example of expectation and another of intention to end life are given below

Expectation: A GP reported on the care of a woman in her 70s who died from a neurological condition affecting her brain in her own home. A decision was taken not to give antibiotics for a chest infection and in the last few days all other medication was withheld. In taking the decision about antibiotics it was felt that this action would probably or certainly hasten the end of the patient's life, and in the event was felt to have shortened life by less than 24 hours. The decision was not taken because of pain or other symptoms, but because relatives had requested it and further treatment was felt to be both futile and likely to produce further suffering in a context where there was no chance that her condition would improve. The decision was not discussed with the patient who was judged not to have the capacity to understand such a discussion, since she had significant cognitive impairment and at the time of the decision was unconscious. As well as relatives, the decision was discussed with nursing staff. No one made an explicit request for the end of life to be hastened. This doctor felt that euthanasia and physician assisted suicide probably should not be allowed by law, except in the case of physician assisted suicide which the doctor felt probably should be allowed in the presence of an incurable and painful terminal illness. (B0018) 
Intention: A doctor working in a critical care unit reported on the care of a woman in her 60s who died in hospital of pneumonia, associated with breast cancer. A decision was made not to use artificial ventilation and various treatments, including oxygen, renal replacements and cardiac inotropes (drugs that affect the strength of heart contractions) were withdrawn. Morphine was given, with a strong increase on the day of death, and a benzodiazepine. The withholding and withdrawing of treatments were done with 'the explicit intention' of hastening the end of life, and the medications given were considered probable or certain to contribute to hastening the end of life. These actions were felt to have shortened life by less than 24 hours. The reasons given for the withdrawal of therapies included the fact that the patient had pain, other symptoms, had no chance of improvement, that further treatment would have been futile and would have increased her suffering, and that the patient and relatives had asked for this. The decision was discussed with the patient and the discussion included the likely effect on length of life. Discussions with medical colleagues, nursing staff and relatives were also reported. The patient had made a clear request for the end of her life to be hastened as had relatives and nursing staff. A GP, a specialist in pain relief, and a spiritual caregiver, as well as nurses and relatives had been involved in her care in the last month of life. The doctor had mixed views about euthanasia and physician assisted suicide, feeling that euthanasia in the presence of an incurable and painful illness ought to be allowed, but being opposed to physician-assisted suicide or euthanasia where no such illness was present. (E0673) 


\section{Making a request for a hastened death}

In $9.8 \%$ (277/2809) of cases where doctors were able to answer the question about this, they reported that their patient had expressed a wish for the end of his or her life to be hastened, $4.2 \%$ agreeing this was 'clearly' expressed and a further 5.6\% agreeing it was 'not very clearly' expressed. Doctors in these cases were asked if the wish had reduced or disappeared over time and $74 \%$ of those answering (198/268) said 'no'. For $21 \%(55 / 268)$ the wish was said to have reduced in response to care provided and 6\% (16/268) said that this had happened for some other reason.

Table 5: Patients expressing a wish for the end of life to be hastened

Table 5 shows that doctors were more likely to report a request where the patient was aged 60-79 years and where the death had occurred in a hospice/PCU or private home. Where the cause of death was cancer, requests were also common. Where a hospice/PCU was the place of death, doctors were less likely to report the request having persisted (54.5\% 18/33 in hospice/PCU versus 76.6\%; 177/231 other deaths; $X^{2}$ test; $\left.\mathrm{p}=.007\right)$ and to say that the request had been reversed because of the care that was then provided $\left(39.4 \%\right.$; $13 / 33$ versus $18.2 \%$; $42 / 231$ of other deaths; $X^{2}$ test; $\mathrm{p}=.005)$. Not having dementia and being judged to have capacity were associated with a higher likelihood of making a request. 


\section{Doctors' reasons}

Where doctors said that their decision had involved an expectation or intention to hasten the end of life, they were asked to indicate the most important reasons for taking the decision. 1000 of the 1036 doctors who took such decisions indicated this. Table 6 shows these separately for decisions taken with an expectation or intention to end life. The right hand column shows that the perception that there was no chance of improvement and that treatment would have been futile are the most common reasons for taking a decision of this sort. The expressed wishes of relatives and patients are the least likely to be given as most important reasons, although they are factors in about a quarter of cases. The perception of no chance of improvement is associated with intention to end life; the presence of pain and other symptoms, and the reporting of a request from a patient is associated with decisions involving expectation rather than intention.

Table 6: Reasons identified by 1000 doctors as the most important in making decisions taken with expectation or intention to hasten death: proportion saying 'yes' to each reason 


\section{Communication about end-of-life decisions}

Table 7 shows, first, that where doctors intended to hasten the end of life they were less likely to report having discussed the decision with a patient. The table then shows that where there was no discussion, patients were usually judged to have lacked the capacity to take part in such discussions. Where the decision was discussed with the patient, this was more likely to involve the potential for shortening life in cases involving intention. Nearly two-fifths of doctors who discussed with the patient indicated that decisions expected or intended to affect the length of life were taken in response to a request from a patient, almost always a verbal one. Discussion with a range of people other than the patient of the potential for hastening the end of life was more likely to occur in cases where the intention to hasten the end of life was present.

Table 7: Communication with patients and others, by expectation and intention

Doctors who reported decisions with a degree of intention to hasten the end of life but no discussion with the patient were particularly likely to be working in hospital specialties (76.9\% of 146 such cases were reported by hospital doctors, although only $54.1 \%$ of doctors reporting a death were in hospital specialties (figures exclude specialists in care of elderly)). Of 112 hospital doctors giving further details of their specialty who reported this pattern of intention with no discussion, $36(31.9 \%)$ were working in specialties associated with intensive care, although this specialty only comprised $6.9 \%$ of the 1487 hospital doctors who reported on a patient who had died and gave further details of their specialty. No oncologists reported such cases, 
although these formed $8.1 \%(121 / 1487)$ of hospital doctors reporting on patients who had died. A case picked from those seen by ICU doctors where there was an intention to hasten the end of life but no discussion is as follows:

A doctor specialising in intensive care reported on the death of a man in his 80s who died in hospital from a head injury. Vasosuppressive drugs and CPR were withheld and artificial ventilation support was withdrawn. The patient was continuously and deeply sedated for three days before death using midazolam, morphine and another drug as this was part of the normal treatment for a brain injury. The withdrawal of ventilation was done with the explicit intention of hastening the end of life because there was no chance of improvement and further treatment was judged futile. This was judged to have shortened life by less than 24 hours. The decision was not discussed with the patient because he was unconscious, but it was discussed with other medical colleagues, nurses and the patient's relatives, the last of whom had made an explicit request for the end of life to be hastened. For all four questions about assisted dying, the doctor thought this 'probably should' be allowed by law. E0496

\section{Discussion}

Concerning the first research question, this study has established that the majority of the deaths reported by these doctors involved an end-of-life decision, with a significant minority involving the expectation, or at least some intention, that these would hasten the end of life. Palliative care specialists were particularly unlikely to 
report decisions taken which they expected or intended to end life. Doctors working in intensive care units were particularly likely to report such decisions. Other evidence supports the finding of the present study that medical actions taken with the intention of ending life affect a significant proportion of deaths in ICU settings (Sprung, Cohen, Sjokvist, Baras, Bulow, Hovilehto et al, 2003).

The second research question concerned the role played by religious beliefs and other attitudes in clinical decision-making. The results show that religious beliefs and attitudes towards the legalisation of assisted dying are associated with the incidence of end-of-life decisions estimated to be likely to have a life-shortening effect. Doctors who said they were religious or who opposed the legalisation of assisted dying were less likely to report decisions where they expected or intended to hasten the end of life. This may be because sanctity of life is a more pressing concern for these doctors than quality of life and may be a cause for concern if this results in patients with similar needs and preferences receiving different treatment.

Third, as in previous studies (Seale \& Addington-Hall, 1995b; Emanuel 2002; Marquet, Bartelds, Visser et al, 2003), this study finds that patients in hospices and palliative care units, and dying from cancer, are particularly likely to be reported as having made requests for an assisted death. Actions taken where doctors expected or intended to end life were nevertheless relatively rarely reported for these patients. Palliative care specialists reported a high rate at which patients making such requests changed their minds in response to care provided, a pattern which is consistent with the view that care in such settings aims to address the fears that lie behind such requests. 
Patients and relatives being reported as having requested a hastened death is associated with a higher rate of decisions taken where the doctor expected or intended to hasten the end of life. Additionally, a proportion of doctors reporting a decision of this sort indicated that this was done because of a patient's or relative's request (though only very occasionally was this request made in written form). On the one hand, this suggests that doctors are responsive to what patients and relatives say they want. On the other hand, such requests are likely to be more common when suffering is high, and some such decisions will have been made in response to this suffering rather than in response to the request. On the whole, though, the findings are consistent with the view that these doctors work in a context where shared decisionmaking is the norm. The doctors appear particularly likely to discuss their decisions with others, including patients (where they were capable of such discussion), relatives and other health care staff.

Finally, and in relation to the 'slippery slope' argument that permeates much of the debate between legislators in the UK and elsewhere when assisted dying is discussed (Lewis, 2007) the results provide little support for the view that the lives of vulnerable elderly people are being devalued so that the deaths of such people are unduly hastened. Decisions which doctors expected or intended to end life are not significantly more often reported amongst the very elderly, amongst women, people dying in care homes or in cases where dementia was judged to be present. The fact that such decisions were more common amongst people judged to lack capacity, and that these decisions were often not discussed with the patient, reflects the fact that many of these will have been in intensive care settings, deeply sedated (Seale, 2009b) 
or unconscious by virtue of their condition. In these situations the views of relatives as well as other medical and nursing staff become influential.

\section{Conclusion and study limitations}

This study provides a cross-sectional 'snapshot' of a complex and changing medical culture, where the parameters of ethical decision-making appear to vary quite significantly across different health care settings and different patients within those settings. Debates conducted at a general level about the ethics of end-of-life care, concerning for example the issue of sanctity versus quality of life, or the principles that might be used to decide upon whether to withdraw or withhold treatment, or to provide treatments that may relieve suffering but also contribute to the ending of life, may be sharpened by empirical information about the variable contexts in which such decisions take place.

As well as providing no evidence of a 'slippery slope' phenomenon, about which both ethicists and legislators have expressed concerns, this survey provides no evidence to support 'strong' claims that doctors in large numbers are either ignoring their patients' wishes or carrying them out uncritically. Instead, we see that doctors are sometimes willing to take actions that they think will hasten the end of life, but do so with a degree of caution and consultation that is particularly characteristic of UK medical practice (Seale, 2006).

It should be recognised, though, that these data are not the product of direct observation of doctors' actions. In replying to a postal questionnaire, there is 
considerable leeway for respondents to interpret and report their actions in the light of underlying preferences. It is, for example, possible that palliative care specialists take similar decisions to doctors elsewhere, but are less likely to believe that these actions are likely to end life. This may be because their knowledge of morphine as a drug that does not contribute to the hastening of death when competently administered (Sykes and Thorne, 2003) is better than that of doctors who are less knowledgeable about the effects of this drug. It could be that doctors with no religious belief are practising in ways that are similar to religious doctors, but are simply more willing to perceive their actions as contributing to the ending of life. Further, the investigation of nonresponse showed that the sample is skewed towards cancer deaths, partly because doctors felt the questionnaire was only relevant to terminal illness, and perhaps also because they tended to pick such cases on which to report rather than following strictly to report on the last case they had attended. In addition, the overall low response rate suggests caution in interpreting the results as, in spite of the investigation of the characteristics of non-responders, there may be significant characteristics not measured in the non-responder survey on which responders and non responders differed.

The method used in this study is therefore a relatively crude instrument but it has the advantage of rapidly summarising suggestive trends, so may therefore help focus further studies aiming to provide more in-depth analyses of individual cases. In particular, the contrast between end-of-life decision-making in hospital settings such as the intensive care unit, and palliative care settings (from which context much policy concerning end-of-life care is derived) deserves further investigation, perhaps by methods that involve closer observation of medical practices in individual cases. 


\section{Ethical approval}

Ethical approval for this study was granted by the South East Research Ethics Committee REC 07/H1102/94.

\section{References}

Bilsen, J., van ver Stichele, R., Broeckaert, B., Mortier, F., \& Deliens, L. (2007).

Changes in medical end-of-life practices during the legalization process of euthanasia in Belgium. Social Science \& Medicine, 65, 803-808

Bosshard, G., Fischer, S., \& Bär, W. (2002). Open regulation and practice in assisted dying: how Switzerland compares with the Netherlands and Oregon. Swiss Medical Weekly, 132, 527-534.

Bosshard, G., Ulrich, E., \& Bär, W. (2003). 748 cases of suicide assisted by a Swiss right-to-die organisation. Swiss Medical Weekly, 133, 310-317.

Carlson, B., Simopoulos, N., Goy, E.R., Jackson, A., and Ganzini, L. (2005). Oregon hospice chaplains' experience with patients requesting physician-assisted suicide. Journal of Palliative Medicine, 8, 6, 1160-1166.

Clery, E., McLean, S., \& Phillips, M. (2007). Quickening death: the euthanasia debate. In A. Park, J. Curtice, K. Thomson, M. Phillips, \& M. Johnson. (Eds.), British 
Social Attitudes: perspectives on a changing society. $23^{\text {rd }}$ Annual Report. (pp. 32554), London: Sage.

Dickinson., G.E., Clark, D., Winslow, M., \& Marples, R. (2005). US physicians' attitudes concerning euthanasia and physician-assisted death: a systematic literature review. Mortality, 10, 43-52.

Dickinson., G.E., Lancaster, C.J., Clark, D., Ahmedzai, S.H., \& Noble, W. (2002). UK physician's attitudes toward active voluntary euthanasia and physician-assisted suicide. Death Studies, 26, 479-490.

Emanuel, E.J. (2002). Euthanasia and physician-assisted suicide: a review of the empirical data from the United States. Archives of Internal Medicine, 162, 142-152

Finlay, I. (2006). The proposed Assisted Dying Bill in the UK: a response to Lord Joffe. Palliative Medicine, 20, 115-118

Fischer, S., Miccinesi, G., Hornung, R., Bosshard, G., Deliens, L., van der Heide, A., Nilstun, T., Norup, M., \& Onwuteaka-Philipsen, B.D. (2006). Responders and nonresponders in a study on medical end-of life decisions in Denmark, the Netherlands, Sweden and Switzerland. Social and Preventive Medicine, 51, 24-33.

Frei, A., Schenker, T.A., Finzen, A., Kräuchi, K., Dittman, V., \& Hoffman-Richter, U. (2001). Assisted suicide as conducted by a 'Right-to-Die' society in Switzerland: a descriptive study of 43 consecutive cases. Swiss Medical Weekly, 131, 375-380. 
Ganzini, L. Fenn, D.S., Lee, M.A., Heintz, R.T., \& Bloom., J.D. (1996). Attitudes of Oregon psychiatrists toward physician-assisted suicide. American Journal of Psychiatry, 153, 11, 1469-1475.

Ganzini. L, Harvath, T.A., Jackson, A., Goy, E.R., Miller, L.L. \& Delorit, M.A. (2002). Experiences of Oregon nurses and social workers with hospice patients who requested assistance with suicide. New England Journal of Medicine, 347, 8, 482-588.

George, R.J.D., Finlay, I.G. \& Jeffrey, D. (2005). Legalised euthanasia will violate the rights of vulnerable patients. British Medical Journal, 331, 684-5.

Georges, J.J., Onwuteaka-Philipsen, B.D., van der Heide, A., van der Wal, G., \& van der Maas, P.J. (2006). Physician's opinions on palliative care and euthanasia in the Netherlands. Journal of Palliative Medicine, 9, 1137-1144

Kemp, N. D.A. (2002). 'Merciful Release', the history of the British euthanasia movement. Manchester: Manchester University Press.

Lewis, P. (2007). Assisted dying and legal change. Oxford: Oxford University Press.

Marquet, R.L., Bartelds, A., Visser, G.J., Spreeuwenberg, P. \& Peters, L. (2003). Twenty five years of requests for euthanasia and physician assisted suicide in Dutch general practice: trend analysis. British Medical Journal, 327, 201-202. 
Miccinesi, G., Fischer, S., Paci, E., Onwuteaka-Philipsen, B.D., Cartwright, C., van der Heide, A., Nilstun, T., Norup, M. \& Mortier, F. on behalf of the EURELD consortium. (2005). Physicians' attitudes towards end-of-life decisions: a comparison between seven countries. Social Science \& Medicine, 60, 1961-1974.

Miller, L.L., Harvath, T.A., Ganzini, L., Goy, E.R., Delorit, M., \& Jackson, A. (2004). Attitudes and experiences of Oregon hospice nurses and social workers regarding assisted suicide. Palliative Medicine, 18:685-691.

Saunders, C. (1992). Voluntary euthanasia. Palliative Medicine, 6, 1-5.

Schmidt. T,A., Zechnich, A.D., Tilden, V.P., Lee, M.A., Ganzini, L., Nelson, H.D., \& Tolle, S.W. (1996). Oregon emergency physicians' experiences with, attitudes toward, and concerns about physician-assisted suicide. Academic Emergency Medicine, 3, 938-945.

Seale, C. (2006). Characteristics of end-of-life decisions: survey of UK medical practitioners. Palliative Medicine, 20, 653-659.

Seale, C. (2009a). Legalisation of euthanasia or physician-assisted suicide: survey of doctors' attitudes. Palliative Medicine, 23, 205-212

Seale, C. (2009b). Continuous deep sedation in UK medical practice: descriptive study. Forthcoming in Journal of Pain and Symptom Management 
Seale, C. \& Addington-Hall, J. (1995a). Dying at the best time. Social Science and Medicine, 40,5, 589-595.

Seale, C. \& Addington-Hall, J. (1995b). Euthanasia: the role of good care, Social Science and Medicine, 40, 5, 581-587.

Slome, L.R., Mitchell, T.F., Charlebois, E., Benevedes, J.M., \& Abrams, D.I. (1996). Physician assisted suicide and patients with human immunodeficiency virus disease. New England Journal of Medicine, 336, 417-421.

Sprung, C.L., Cohen, S.L., Sjokvist, P., Baras, M., Bulow, H., Hovilehto, S., Ledoux, D., Lippert, A., Maia, P., Phelan, D., Schobersberger, W., Wennberg, E., \& Woodcock, T. (2003). End-of-life practice in European intensive care units. Journal of the American Medical Association, 290, 6, 790-797.

Sykes, N., \& Thorne, A. (2003). The use of opioids and sedatives at the end of life. The Lancet Oncology, 4, 312-318.

van ver Heide, A., Onwuteaka-Philipsen, B.D., Rurup, M.L., Buiting, H.M., Van Delden, J.J.M., Hanssen-De Wolf, J.E., Janssen, A.G.J.M., Pasman, H.R.W., Rietjens, J.A.C., Prins, C.J.M., Deerenberg, I.M., Gevers, J.K.M., Van Der Maas, P.J., \& Van Der Wal, G. (2007). End-of-life practices in the Netherlands under the Euthanasia Act. New England Journal of Medicine, 356, 19, 1957-1965. 


\section{Box 1: Questions about end-of-life decisions}

Q1. Concerning this death, did you or a colleague:

Q1a. withhold a treatment* (or ensure that this was done)?

Q1b. withdraw a treatment* (or ensure that this was done)?

Q1c. use any drug to alleviate pain and/or symptoms?

Q2a. In withholding a treatment, did you or your colleague consider it probable or certain that this action would hasten the end of the patient's life? Q2b. In withdrawing a treatment, did you or your colleague consider it probable or certain that this action would hasten the end of the patient's life?

Q3. Concerning the drugs used to alleviate symptoms, (Question 1c), were these administered

Q3a. knowing this would probably or certainly hasten the end of life?

Q3b. partly intending to end life?

Q4a. In withholding a treatment, did you or your colleague have the explicit intention of hastening the end of life?

Q4b. In withdrawing a treatment, did you or your colleague have the explicit intention of hastening the end of life?

Q5. Was death caused by the use of a drug prescribed, supplied or administered by you or a colleague with the explicit intention of hastening the end of life (or of enabling the patient to end his or her own life?)

* in this study 'treatment' includes cardio-pulmonary resuscitation (CPR), artificial feeding and/or hydration 
Table 1: Expectation and intention to hasten death, by doctors' characteristics (percentages)

\begin{tabular}{|c|c|c|c|c|c|}
\hline & $\begin{array}{l}\text { None } \\
\text { (b) }\end{array}$ & $\begin{array}{l}\text { Expec } \\
\text { (c) }\end{array}$ & $\begin{array}{l}\text { Intend } \\
\text { (d) }\end{array}$ & $\begin{array}{l}\text { Total } \\
(=100\end{array}$ & $\underset{\%)}{\mathrm{p} \text { value }}$ \\
\hline \multicolumn{6}{|l|}{ Age of doctor } \\
\hline Less than 36 & 56.4 & 38.0 & 5.6 & 408 & \\
\hline $36-55$ & 60.9 & 30.7 & 8.3 & 1815 & \\
\hline $56+$ & 61.7 & 28.7 & 9.6 & 376 & $\mathrm{p}=.016$ \\
\hline \multicolumn{6}{|l|}{ Gender of doctor } \\
\hline Male & 57.1 & 33.2 & 9.6 & 1640 & \\
\hline Female & 66.1 & 28.5 & 5.4 & 940 & $\mathrm{p}<.0005$ \\
\hline \multicolumn{6}{|l|}{ Specialty } \\
\hline GP & 67.5 & 27.6 & 4.9 & 710 & \\
\hline Palliative care & 89.9 & 9.3 & 0.8 & 247 & \\
\hline Care of elderly & 61.4 & 30.9 & 7.6 & 262 & \\
\hline Other hospital & 51.3 & 37.7 & 11.0 & 1394 & $\mathrm{p}<.0005$ \\
\hline
\end{tabular}

Support for legalisation of assisted dying

Strong support

Moderate support

$49.1 \quad 33.1 \quad 17.8$

163

$\begin{array}{llll}52.2 & 36.9 & 10.9 & 696\end{array}$

Moderate opposition

$\begin{array}{lll}55.3 & 36.2 & 8.5\end{array}$

828

Strong opposition

$\begin{array}{lll}73.4 & 23.2 & 3.4\end{array}$

$850 \quad \mathrm{p}<.0005$

Religiosity

Religious

$\begin{array}{lll}67.6 & 27.9 & 4.5\end{array}$

330

Neutral

$\begin{array}{lll}61.0 & 30.9 & 8.1\end{array}$

1568

Non religious

$49.9 \quad 39.0 \quad 11.1$

$513 \quad \mathrm{p}<.0005$

*Where totals do not add to 2855 , missing data on these questions was recorded Statistical significance based on chi-squared test 
Table 2: Expectation and intention to hasten death, by patients' characteristics (percentages)

\begin{tabular}{|c|c|c|c|c|c|}
\hline \multirow[b]{2}{*}{ Age } & \multirow[t]{2}{*}{$\begin{array}{l}\text { None } \\
\text { (b) }\end{array}$} & \multirow{2}{*}{\multicolumn{2}{|c|}{$\begin{array}{l}\text { Expect Intend } \\
\begin{array}{ll}\text { (c) } & \text { (d) }\end{array}\end{array}$}} & \multicolumn{2}{|c|}{$\begin{array}{l}\text { Total } * \text { p value } \\
(=100 \%)\end{array}$} \\
\hline & & & & & \\
\hline $0-59$ & 64.7 & 27.0 & 8.3 & 519 & \\
\hline $60-79$ & 58.7 & 32.9 & 8.4 & 1179 & \\
\hline $80+$ & 59.8 & 32.6 & 7.5 & 904 & $\mathrm{p}=.125$ \\
\hline \multicolumn{6}{|l|}{ Gender } \\
\hline Male & 60.9 & 31.9 & 7.2 & 1210 & \\
\hline Female & 60.1 & 31.2 & 8.7 & 1358 & $\mathrm{p}=.374$ \\
\hline \multicolumn{6}{|l|}{ Place of death } \\
\hline Hospital & 54.9 & 35.0 & 10.1 & 1701 & \\
\hline Hospice/PCU** & 82.2 & 15.9 & 1.8 & 276 & \\
\hline Care home & 73.1 & 20.4 & 4.2 & 167 & \\
\hline Private home & 59.5 & 29.8 & 5.2 & 451 & $\mathrm{p}<.0005$ \\
\hline \multicolumn{6}{|l|}{ Cause of death } \\
\hline Cancer & 66.3 & 28.2 & 5.4 & 1194 & \\
\hline Cardiovascular & 54.7 & 35.3 & 10.0 & 468 & \\
\hline Respiratory & 53.0 & 39.3 & 7.8 & 270 & \\
\hline Nervous system & 59.0 & 33.1 & 7.9 & 139 & \\
\hline Other & 59.0 & 35.5 & 14.2 & 394 & $\mathrm{p}<0.0005$ \\
\hline \multicolumn{6}{|l|}{ Dementia*** } \\
\hline Yes & 57.6 & 34.1 & 8.2 & 170 & \\
\hline No & 59.8 & 32.1 & 8.1 & 2296 & $\mathrm{p}=.326$ \\
\hline \multicolumn{6}{|l|}{ Had capacity } \\
\hline Yes & 57.3 & 37.5 & 5.2 & 1056 & \\
\hline No & 48.4 & 37.3 & 14.2 & 964 & $\mathrm{p}<.0005$ \\
\hline
\end{tabular}


Table 3: Expectation and intention to hasten death, by requests for a hastened death (percentages)

$$
\begin{aligned}
& \text { None Expect Intend Total* p value } \\
& \text { (b) (c) (d) } \quad(=100 \%)
\end{aligned}
$$

From patient

$\begin{array}{llllll}\text { Yes } & 39.1 & 46.9 & 14.0 & 271 & \\ \text { No } & 62.6 & 30.0 & 7.4 & 2310 & \mathrm{p}<.0005\end{array}$

From relative

$\begin{array}{llllll}\text { Yes } & 34.3 & 36.2 & 29.5 & 105 & \\ \text { No } & 60.9 & 31.8 & 7.2 & 2435 & \mathrm{p}<.0005\end{array}$

From nurse

or other care staff

Yes

$\begin{array}{llll}37.1 & 20.0 & 42.9 & 35\end{array}$

No

$\begin{array}{lllll}60.1 & 32.2 & 7.7 & 2506 & \mathrm{p}<.0005\end{array}$

*Where totals do not add to 2855 , missing data on these questions was recorded Statistical significance based on chi-squared test 
Table 4: Logistic regression of (c) expectation or (d) intention to hasten death versus decisions with (b) no expectation or intention, on specialty, cause of death, request for a hastened death, capacity and attitude to legalisation of assisted dying.

In favour of legalising assisted dying*

OR $(95 \% \mathrm{CI}) \quad \mathrm{p}$ value

Request for hastened death reported $* *$

$1.33 \quad 1.19-1.48 \quad<.0005$

Did not have capacity

$2.80 \quad 2.08-3.77 \quad<.0005$

$1.36 \quad 1.10-1.68 \quad .005$

Specialism

Palliative care 1

Elderly

1

General practice

$\begin{array}{lll}4.76 & 2.67-8.48<.0005\end{array}$

Other hospital

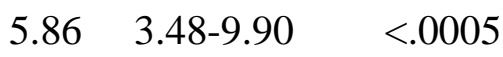

$8.53 \quad 5.12-14.22<.0005$

Cause of death

Cancer

1

Cardiovascular

$\begin{array}{lll}1.13 & 0.85-1.51 \quad .38\end{array}$

Respiratory

$\begin{array}{lll}1.23 & 0.88-1.73 \quad .22\end{array}$

Nervous system

$\begin{array}{lll}1.05 & 0.68-1.63 \quad .83\end{array}$

Other

$1.32 \quad 0.98-1.76 \quad .07$

$\mathrm{N}=1850$

$\mathrm{OR}=$ odds ratio $\mathrm{CI}=$ confidence interval

* four point ordinal scale, so OR represents change in odds per point of scale

** request from either patient, relative, nurse or someone else 
Table 5: Patients expressing a wish for the end of life to be hastened

Age

$0-59$

60-79

5.9

11.6

9.9

$\mathrm{N}^{*} \quad \mathrm{p}$ value

$(=100 \%)$

$80+$

$\%$ requesting

$$
(=100 \%)
$$

Place of death

Hospital

8.5

564

1237

$995 \mathrm{p}=.001$

Hospice/PCU*

12.6

1854

Care home

8.2

Private home

13.5

278

183

$473 \mathrm{p}=.003$

Missing

Cause of death

Cancer

11.7

1218

Cardiovascular

5.7

529

Respiratory

12.5

296

Nervous system

12.6

151

Other

7.2

$458 \quad \mathrm{p}<.0005$

Dementia

Yes

6.7

194

No

10.1

$2457 \mathrm{p}=.127$

Had capacity

Yes

16.3

1053

No

5.6

$957 \quad \mathrm{p}<.0005$

*PCU = palliative care unit

*Where totals do not add to 2855 , missing data on these questions was recorded 
Table 6: Reasons identified by 1000 doctors as the most important in making decisions taken with expectation or intention to hasten death: proportion saying 'yes' to each reason

\begin{tabular}{|c|c|c|c|c|}
\hline & $\begin{array}{l}\text { Expe } \\
\text { (c) } \\
\%\end{array}$ & $\begin{array}{l}\text { Intend } \\
\text { (d) } \\
\%\end{array}$ & $\begin{array}{l}\text { Both } \\
\%\end{array}$ & $\mathrm{p}$ value* \\
\hline No chance of improvement & 68.7 & 76.1 & 70.2 & $=.038$ \\
\hline Treatment would have been futile & 65.7 & 70.7 & 66.7 & $=.170$ \\
\hline Expected further suffering & 41.8 & 42.9 & 42.0 & $=.763$ \\
\hline $\begin{array}{l}\text { Further treatment would have } \\
\text { increased suffering }\end{array}$ & 40.6 & 45.4 & 41.6 & $=.220$ \\
\hline Patient had pain & 40.1 & 27.8 & 37.6 & $=.001$ \\
\hline Patient had other symptoms & 32.8 & 22.0 & 30.6 & $=.003$ \\
\hline Request or wish of relatives & 24.5 & 25.7 & 24.8 & $=.695$ \\
\hline Request or wish of the patient & 24.2 & 16.1 & 22.5 & $=.014$ \\
\hline Total $(=100 \%)$ & 795 & 205 & 1000 & \\
\hline
\end{tabular}


Table 7: Communication with patients and others, by expectation and intention*

Expect Intend All p value

(c) (d)

Discussed with patient

Total $(=100 \%)$

$47.6 \% 27.4 \%$

$788 \quad 201$

$43.5 \%$

989

$<.0005$

Of 516 who did not discuss

with patient

Patient lacked capacity

$84.7 \% 94.9 \%$

$379 \quad 137$

$87.4 \%$

$516=.002$

Of 419 who discussed with patient

Discussion included potential

for hastening end of life

$61.3 \% 77.4 \%$

$63.0 \%$

$=.023$

Decision made in response

to explicit request from patient $* * 36.5 \% 42.6 \%$

Total $(=100 \%)$

36454

$37.3 \%=.391$

Discussions with others

about potential for hastening

end of life

Medical colleagues

$57.1 \% \quad 63.8 \%$

$58.5 \%$

$=.091$

Nursing staff / other caregivers

$62.5 \% 77.4 \%$

$65.5 \%$

$<.0005$

Partner/relatives of patient

$66.8 \% 75.4 \%$

$68.6 \%$

$=.022$

Someone else

$2.2 \% \quad 6.6 \%$

$3.1 \%$

$=.002$

None of these

$10.3 \% 3.1 \%$

Total $(=100 \%)$

$760 \quad 196$

$8.8 \%$

$=.002$

*For some cases data is missing for the communication variables in this table, so totals do not add to the 825 'expected' and 211 'intended' reported in the text.

**5/419 involved a written request. This was a different question from the one shown in Table 6, which asked if a patient request was a 'most important' reason. 